\title{
News Briefs
}

\section{Developments}

\section{NBS CONTRIBUTING TO CANCER PREVENTION STUDY}

Can supplemental doses of certain vitamins and minerals reduce cancer risks? NBS is helping answer this question by contributing to a larger government study - sponsored by the National Cancer Institute ( $\mathrm{NCI}$ - that is examining the cancer preventive properties of "micronutrients." These are compounds, such as vitamins A, C, and E, which may help prevent some tumors in persons at high risk due to lifestyle or occupational exposure, or in those who have had cancer but now are free of the disease.

Accurate measurements of nutrients in blood serum are crucial to the NCI study, so NBS has established a "quality assurance" program to ensure that the 20 laboratories participating in the program make reliable nutrient measurements in blood samples. To perform these quality checks, NBS sends samples with known values to the labs for analysis. If results are inaccurate, the Bureau suggests ways to improve. Ultimately, serum nutrient values will be correlated with the occurrence or recurrence of cancer in populations being studied.

For further information, contact Willie May, National Bureau of Standards, Gaithersburg, MD 20899 or Herbert Pierson, National Cancer Institute, Bethesda, MD 20892.

\section{AUTOMATION LABORATORY COMPLETED} NBS has completed construction work on a unique automation laboratory designed as a proving ground for the technology of America's factories in the 21st century. This laboratory, called the
Automated Manufacturing Research Facility (AMRF), will aid both large and small American manufacturers. The facility is a collaborative venture involving private industry, universities, and other government agencies, most notably the U.S. Navy.

Under construction since 1983, the AMRF is a research laboratory designed to study standard methods to link different computerized machines. It also is used to help manufacturers improve quality control by experimenting with efficient and reliable methods for monitoring the performance of automated machinery.

For further information, contact John Simpson, National Bureau of Standards, Gaithersburg, MD 20899.

\section{PATENT GRANTED FOR HYDROPHOBIC DENTAL COMPOSITES}

A patent has been granted for a dental composite system developed by NBS that offers dentists a material with improved wear and stability, as well as greater resistance to surface staining and discoloration. The composite system contains a high concentration of bulky fluorinated monomers that are highly immune to chemical softening and degradation in the oral environment.

Hydrophobic Dental Composites Based on a Polyfluorinated Dental Resin, Patent No. $4,616,073$, was developed by NBS researcher Joseph M. Antonucci for the National Institute of Dental Research. The resin system can be used in two different ways; it can be cured photochemically with a dental light pen, or it can be cured as a two-part monomer system. Among the other advantages of this type of dental composite resin system based on hydrophobic polymer matrices are its low water sorption and low shrinkage especially at composite-cavity interfaces when used in dental restorations. 


\section{NBS DEVELOPS NEW WAY TO MEASURE STEEL ROUGHNESS}

NBS researchers have developed a new way to measure the roughness of steel which has been "blasted" with an abrasive, such as sand. Blasting is a cleaning process which prepares a material for a coating. Surface roughness affects the life of the coating, but the exact relationship is not well understood since precise measurements are difficult and time consuming to make.

The NBS method uses an infrared thermographic camera coupled with a computer image processor to produce a depth profile-a pattern of the peaks and valleys - of the steel. Surface roughness can then be mathematically described. The procedure is faster and more precise than current methods. In addition, the measurements can be made without touching the material. Currently, the NBS researchers are experimenting with the procedure to see if it can be used to characterize engineered surfaces and whether it can be adapted to in-line processing such as spray-painting assembly lines.

For further information, contact Jonathan Martin, National Bureau of Standards, Gaithersburg, MD 20899.

\section{ELECTROMAGNETIC COMPATIBILITY AND INTERFERENCE MEASUREMENTS}

Electromagnetic compatibility/interference measurements are used to determine how electronic equipment undesirably generates or is affected by electromagnetic radiation. Reliable, accurate EMC/EMI measurements are essential to the design and operation of a broad variety of electronic equipment and products used in automotive, household, industrial, business, and military applications.

A new NBS publication [1] includes the text material for a short course in EMC/EMI measurements presented by NBS. It sets out basic EMC measurements, and includes chapters on measurements made using transverse electromagnetic (TEM) cells, anechoic chambers, open fields, reverberating chambers, and EM probes. Other chapters deal with measurement of the shielding effectiveness of materials, out-of-band EMC problems, conducted EMI, and complicated electromagnetic environments.

Reference

[1] NBS TN 1099, Electromagnetic Compatibility and Interference Metrology, Superintendent of Documents, U.S. Govermment Printing Office, Washington, DC 20402 (\$8.50 prepaid, order by Stock No. 003-003-02760-0).

\section{ARMSTRONG WORLD TO PERFORM POLYMER RESEARCH AT NBS}

Armstrong World Industries, Lancaster, PA, has established a Research Associate Program at NBS to study the permeability of polymer composites to freon gases. An Armstrong researcher will use the NBS computerized volatile gas permeation facility to measure the gas transport properties of a series of polymers used as components in polymer blends. The information will be used to process blends into thermal insulating foams. The NBS Research Associate Program provides an opportunity for researchers from universities, industry, trade associations, and other organizations to conduct cooperative work at the Bureau on projects of mutual interest, with salaries paid by the sponsor.

For further information on the Research Associate Program, contact David Edgerly, National Bureau of Standards, Gaithersburg, MD 20899, telephone: 301/975-3087.

\section{ASSESSING ELECTROEXPLOSIVE DEVICE VULNERABILITY}

Hot-wire electroexplosive devices (EEDs) are electrically fired explosive initiators. They are used as automotive air bag initiators, separation devices in aerospace applications (explosive bolts), and many other military, mining, and construction applications. A new and rigorous approach for assessing an EED's vulnerability to pulsed electromagnetic interference is given in a recent NBS report [1]. This method uses statistical theory and thermodynamic modeling to determine the probability that an electrical pulse of a given duration and power will detonate the EED, and to determine thermodynamic parameters. The "Firing Likelihood Plot" is introduced to represent an EED's characteristic in a readily interpretable manner.

\section{Reference}

[1] NBS TN 1094, A Statistical Characterization of Electroexplosive Devices Relevant to Electromagnetic Compatibility Assessment, Superintendent of Documents, U.S. Government Printing Office, Washington, DC 20402 ( $\$ 2.75$ prepaid, order by Stock No. 003-003-02744-8).

\section{MEASURING SHIELDING EFFECTIVENESS OF MATERIALS}

The shielding effectiveness of a material is a measure of how well it is able to isolate a region from electromagnetic fields. Shielding is used to protect equipment from outside interference or to reduce 
unwanted emissions from equipment. While traditional metal shields have characteristics that are well understood, the recent use of more complex materials with less predictable shielding properties, such as plastic housings and composites, has made measurement of the shielding effectiveness essential.

In a new publication [1], NBS reports on an evaluation of several measurement approaches.

Reference

[1] NBS TN 1095, A Study of Techniques for Measuring the Electromagnetic Shielding Effectiveness of Materials, Superintendent of Documents, U.S. Government Printing OfGice, Washington, DC 20402 ( $\$ 3.50$ prepaid, order by stock No. 003-003-02735-9).

\section{REPORT SUMMARIZES QUALTTY ASSURANCE LITERATURE}

Analytical chemists, laboratory managers, and quality assurance (QA) officials should find a new NBS report useful [1]. It contains abstracts of 160 papers selected as source materials for starting new QA programs or improving existing ones. The papers also are good resources for general guidance in producing reliable analytical chemical measurements. John K. Taylor, who has taught 75 NBS chemical QA workshops to industrial, academic, and government participants over the last 7 years, assembled the report. Taylor, who recently retired after 57 years at NBS, says much has been written on quality assurance of production processes, but considerably less is available about measurement QA, especially about chemical measurements. His goal in writing the 51-page report was to provide a good summary of what is available in chemical QA materials.

\section{Reference}

[1] NBSIR 86-3352, A Collection of Abstracts of Selected Publications Related to Quality Assurance of Chemical Measurements, National Technical Information Service (NTIS), Springfield, VA 22161 (\$11.95 prepaid, order by PB\# 87-106423).

\section{DRAFT FEDERAL OSI STANDARD CIRCULATED FOR REVIEW}

A draft specification for the acquisition of Federal Government computer systems that conform to the Open Systems Inter connection (OSI) standards has been completed by the Government OSI Users Committee, sponsored by NBS. The specification is based on a cooperative effort between NBS and industry to implement emerging OSI standards in commercial, off-the-shelf products, and is compatible with both the Manufacturing Automation Protocol (MAP) and the Technical and Office
Protocols (TOP) which have been developed by industry. NBS is circulating the draft specification to Federal agencies and to industry and standards organizations for review before recommending its adoption as a joint Federal Information Processing Standard/Federal Telecommunication Standard for use in 1987 and 1988 procurements.

For further information, contact Shirley Radack, National Bureau of Standards, Gaithersburg, MD 20899.

\section{Standard Reference Data}

\section{NBS DEVELOPS COMPUTERIZED \\ DATABASE FROM AIChE/DIPPR \\ STANDARD REFERENCE SOURCE \\ ON PURE CHEMICAL COMPOUNDS}

Chemical manufacturers; engineers who design plants; chemical processes, and new products; as well as scientists in industry, government, and universities will be interested in a new computerized standard reference database from NBS on the thermodynamic and physical properties of chemicals.

The new computerized database provides users with quick access to important information on the behavior of substances and their reactions under various pressures and temperatures. It was produced under an agreement between NBS and the American Institute of Chemical Engineers (AIChE).

The database, DIPPR (Design Institute for Physical Property Data), Data Compilation of Pure Compound Properties, 1986, contains information on 39 properties for 346 chemical compounds of high industrial priority. These chemicals were selected by the industry members of AIChE's DIPPR group, a cooperative organization of chemical manufacturers and related companies. The chemicals in the database are considered to be the most important ones to users, based on their volume of production and other economic factors.

Information is provided on the thermodynamic, physical, and transport properties of each chemical. And for each compound included, values are given for 26 single-valued property constants and for 13 properties as functions of temperature, calculated from correlation coefficients.

The database, which is interactive or "conversational" for users, also includes estimates of the accuracy of each property value and provides references to the sources of measured or predicted 
data that were used in selecting the recommended values.

It was automated by the NBS Office of Standard Reference Data from AIChE's 1985 resource book, Data Compilation: Tables of Properties of Pure Compounds. This printed database was prepared for DIPPR by Thomas E. Daubert and Ronald P. Danner of Pennsylvania State University.

The printed reference is one of several cooperative projects on evaluated standard data to be sponsored by industry through DIPPR. NBS has provided technical support to the industrial group since it was established by $\mathrm{AIChE}$ in 1978, particularly in the area of computerized information.

AIChE is a national organization of 60,000 scientists and engineers in research and manufacturing.

NBS Standard Reference Database 11, DIPPR, Data Compilation of Pure Compound Properties, 1986, are one of 11 databases in magnetic tape form that is available from OSRD for lease to individuals, distributors, or subscription search services. For information on fees and lease agreements for DIPPR, or for a list of the other computerized standard reference databases available from NBS, contact: Office of Standard Reference Data, A323 Physics Building, National Bureau of Standards, Gaithersburg, MD 20899, telephone: 301/975-2208.

\section{MICROCOMPUTER FORTRAN PROGRAMS CALCULATE FLUID PROPERTIES}

The thermophysical and transport properties of 12 selected fluids have been programmed in FORTRAN 77 for microcomputers. When any two of pressure, temperature, or density values are input (in single phase regions), or either pressure or temperature (in saturated liquid or vapor states), the programs calculate pressure, density, temperature, internal energy, enthalpy, entropy, specific heat capacities $(\mathrm{Cv}$ and $\mathrm{Cp})$, speed of sound, and in most cases, viscosity, thermal conductivity, and dielectric constant.

The fluids included are helium, hydrogen, nitrogen, oxygen, argon, nitrogen trifluoride, methane, ethylene, ethane, propane, iso- and normal butane. Properties are given over a wide range of temperatures and pressures.

A description and listing of the program, along with sample calculations and a typical computer run, is available in a recent NBS publication [1].

Copies of the program on microcomputer diskette are available for $\$ 400$ from the Office of Standard Reference Data, A320 Physics Building, National Bureau of Standards, Gaithersburg, MD 20899, telephone: 301/975-2208.

\section{Reference}

[1] NBS TN 1097, Interactive FORTRAN Programs for Microcomputers to Calculate the Thermophysical Properties of Twelve Fluids (MIPROPS), Superintendent of Documents, U.S. Government Printing Office, Washington, DC 20402 ( $\$ 4.25$ prepaid, order by stock No. 003-003-02745-6).

\section{NBS Services}

\section{NBS AND USAF SIGN MEMO OF UNDERSTANDING ON MILSTAR}

NBS and the U.S. Air Force have reached agreement on a two-year program to develop millimeter-wave metrology and standards in support of the Milstar Satellite Communications System. Milstar is the next generation of extremely sophisticated military communications satellites. NBS will receive a total of $\$ 2.8$ million over fiscal years 1987 and 1988 to develop measurement services and standards support over a wide range of parameters including millimeter wave power, impedance, noise temperature, antenna gain, and phase noise. The work will be carried out principally in the $19-22$ and $42-46 \mathrm{GHz}$ range. This program will enable NBS to provide interim (special test) measurement services to the three military branches, Milstar contractors, and their subcontractors.

Direct inquiries to Ernest Garner, National Bureau of Standards, Gaithersburg, MD 20899, telephone: 301/975-2007. 


\section{News Reports}

\section{FREE-ELECTRON LASER FACILITY TO BE CONSTRUCTED AT NBS}

An important new national facility for research in physics, materials science, and biomedicine will be constructed at NBS under a congressionally authorized program aimed at exploiting free-electron lasers in biomedical and materials science.

A proposal to build the new facility, submitted jointly by NBS and the Naval Research Laboratory, has been recommended for funding by the Office of Naval Research and the Air Force Office of Scientific Research. The two agencies jointly manage the free-electron laser research program for the Strategic Defense Initiative Organization. That organization would provide $\$ 4.9$ million to build the facility.

A free-electron laser is an exotic light source in which the gases, liquids, or crystals normally used to produce the laser effect are replaced by bunches of electrons traveling through a periodically varying magnetic field. Such lasers are capable of very short, intense bursts of light that can be tuned very finely across a broad range of frequencies.

The new laser will be constructed in the accelerator complex at the NBS laboratories in Gaithersburg, $M D$, and will be driven by the Bureau's 185 $\mathrm{MeV}$ continuous wave $(\mathrm{cw})$ racetrack microtron, which is currently nearing completion. The $\mathrm{cw}$ microtron is an experimental electron accelerator, being built in collaboration with Los Alamos National Laboratory. It will be one of the most powerful high-current $\mathrm{cw}$ accelerators in the world.

When completed in 1990, the free-electron laser will supply light in the wavelength range of 0.2 micrometer to 10 micrometers, with a bandwidth on the order of 0.001 , at average power levels of hundreds of watts. In addition, copious amounts (milliwatts to watts) of coherent UV light will be produced at harmonics of the laser frequency down to wavelengths of approximately $30 \mathrm{~nm}$.
The light will be a continuous train of 3-ps pulses at repetition frequencies of $20 \mathrm{MHz}$ or $100 \mathrm{MHz}$. This pulse length is of particular interest in the study of organic and biological molecules.

The unique properties of the free-electron laser, including broad wavelength tunability, high peak and average power, and extremely short pulse lengths, open up a broad range of exciting new research opportunities in such diverse areas as atomic and molecular physics, surface science, photochemistry, biophysics and biomedicine.

An external advisory panel comprised of senior scientists and managers from the academic, industrial and government sectors will help guide the project.

Plans for the facility call for close collaboration with the medical and materials science communities, including the Uniformed Services University of the Health Sciences, the Food and Drug Administration, the Center for Advanced Research in Biotechnology, and a number of universities in the Washington, DC, metropolitan area.

For further information, contact Samuel Penner, National Bureau of Standards, Gaithersburg, MD 20899. 